\title{
"Understanding the preference of individual retail investors on green bond in India: An empirical study"
}

\begin{tabular}{|c|c|}
\hline \multirow{4}{*}{ AUTHORS } & Dhaval Prajapati \\
\hline & Sushant Malik (D https://orcid.org/0000-0002-9763-8363 \\
\hline & Dharmesh K. Mishra (D https://orcid.org/0000-0002-6434-6153 \\
\hline & R https://publons.com/researcher/2156653/dharmesh-k-mishra/ \\
\hline ARTICLE INFO & $\begin{array}{l}\text { Dhaval Prajapati, Dipen Paul, Sushant Malik and Dharmesh K. Mishra (2021). } \\
\text { Understanding the preference of individual retail investors on green bond in } \\
\text { India: An empirical study. Investment Management and Financial Innovations, } \\
\text { 18(1), 177-189. doi:10.21511/imfi.18(1).2021.15 }\end{array}$ \\
\hline DOI & http://dx.doi.org/10.21511/imfi.18(1).2021.15 \\
\hline RELEASED ON & Tuesday, 16 February 2021 \\
\hline RECEIVED ON & Friday, 04 December 2020 \\
\hline \multirow[t]{2}{*}{ ACCEPTED ON } & Friday, 12 February 2021 \\
\hline & \begin{tabular}{|l|l|l|l|l|} 
EY \\
\end{tabular} \\
\hline LICENSE & $\begin{array}{l}\text { This work is licensed under a Creative Commons Attribution } 4.0 \text { International } \\
\text { License }\end{array}$ \\
\hline JOURNAL & "Investment Management and Financial Innovations" \\
\hline ISSN PRINT & $1810-4967$ \\
\hline ISSN ONLINE & $1812-9358$ \\
\hline PUBLISHER & LLC "Consulting Publishing Company "Business Perspectives" \\
\hline FOUNDER & LLC "Consulting Publishing Company "Business Perspectives" \\
\hline
\end{tabular}

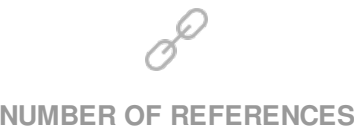

54
NUMBER OF FIGURES

0
NUMBER OF TABLES

7

(C) The author(s) 2021. This publication is an open access article. 


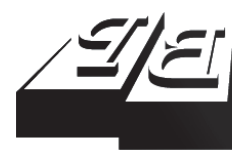

BUSINESS PERSPECTIVES

(O)

LLC "CPC "Business Perspectives" Hryhorii Skovoroda lane, 10, Sumy, 40022, Ukraine www.businessperspectives.org
Received on: $4^{\text {th }}$ of December, 2020 Accepted on: 12 ${ }^{\text {th }}$ of February, 2021 Published on: $16^{\text {th }}$ of February, 2021

( ) Dhaval Prajapati,

Dipen Paul, Sushant Malik, Dharmesh K. Mishra, 2021

Dhaval Prajapati, Post Graduate Student, Energy and Environment, Symbiosis Institute of International Business, Symbiosis International (Deemed University), India.

Dipen Paul, Assistant Professor Symbiosis Institute of International Business, Symbiosis International (Deemed University), India. (Corresponding author)

Sushant Malik, Assistant Professor, Symbiosis Institute of International Business, Symbiosis International (Deemed University), India.

Dharmesh K. Mishra, Associate Professor, Symbiosis Institute of International Business, Symbiosis International (Deemed University), India.

This is an Open Access article, distributed under the terms of the Creative Commons Attribution 4.0 International license, which permits unrestricted re-use, distribution, and reproduction in any medium, provided the original work is properly cited.

Conflict of interest statement: Author(s) reported no conflict of interest

Dhaval Prajapati (India), Dipen Paul (India), Sushant Malik (India),

Dharmesh K. Mishra (India)

\title{
UNDERSTANDING
}

THE PREFERENCE OF INDIVIDUAL

RETAIL INVESTORS ON GREEN

\section{BOND IN INDIA: AN EMPIRICAL STUDY}

\begin{abstract}
The biggest challenge facing countries, including India, is creating and managing an LCR (low carbon resilient) economy, which balances the need for high growth rates and is environmentally sustainable. The green bond market provides investors the means to help change the economy into an LCR economy. The study was undertaken to understand the key drivers and the factors influencing the individual retail investor's decision to invest in green bonds. A survey instrument was designed and administered through the snowball sampling technique to 125 Indian respondents of various age groups who were eligible to invest in the Indian bond market. SPSS software was used to conduct a descriptive analysis followed by regression and conjoint analyses. The study results suggest that the Environmental, Social, and Governance (ESG) rating and credit rating of the green bond issuers are the key factors that influence an individual's investment decision. The findings also highlight that incentives such as tax exemptions and awareness of green bonds also affect an investor's decision. This research stands out as one of the first attempts to understand the Indian retail investors' perception of a green bond.
\end{abstract}

\section{Keywords}

JEL Classification

\section{INTRODUCTION}

In compliance with the United Nations Framework Convention on Climate Change (UNFCCC), also known as the Paris Agreement, India intends to achieve by 2022 the capacity to generate $175 \mathrm{GW}$ of renewable energy from non-conventional sources such as solar, wind, hydro, and bioenergy. India is also committed to reducing the intensity of greenhouse gas (GHG) emission by $33 \%$ to $35 \%$ below the 2005 level per unit GDP by 2030 and developing a carbon sink of 2.5-3 billion tons of $\mathrm{CO}_{2}$ equivalent (Government of India, 2015). To achieve these targets. India has to become a more climate-resilient economy, reduce the emission from waste, implement the Green India mission, increase afforestation, enclose the energy efficiency with the economy, and convince the people to help more in resisting climate change.

The greatest challenge facing the world and India is the management of the transition towards the low carbon resilient (LCR) economy without affecting the rate and diversity of the growth. According to the 'Expert Group on Low Carbon Strategies for Inclusive Growth', which was set up under India's Planning Commission (Currently known as the NITI Ayog), the "Baseline Inclusive Growth" forecasts an average annual GDP growth rate of 7\% between 2007 and 2030. However, the 
Low Carbon Inclusive Growth (LCIG) in GDP is expected to be marginally lower at 6.9\%. However, it can significantly reduce per capita GHG emission from $\mathrm{CO}_{2}$ equivalentemission from the current 3.6 tons per year to 2.6 tonnes equivalent per year by 2030. This emission reduction will be achieved through efforts in several directions. The major means of the reduction are increased energy efficiency and a shift to the exploitation of alternative energy sources. Though the reduction in the GDP growth forecast seems very small, it makes an enormous difference in the monetary value of GDP. LCIG strategy requires an additional investment of US\$ 834 billion at the 2011 prices, which may necessitate the diversion of resources necessary for meeting other needs. It is estimated that the GDP loss caused by this additional investment will be US $\$ 1,344$ billion at 2011 prices (Planning Commission, Government of India, 2014). To raise the resources to meet these challenges, retail participation needs to be encouraged in green bonds to enable sustainable investments in the initiatives to transit towards an LCR economy. The green bond is like any other bond, which is used to raise the fund from investors. However, the difference between the same lies in the use of the income. Unlike any other bonds, green bonds can only be used to finance "green" projects, so defining the term "green" is necessary. According to the Securities and Exchange Board of India (SEBI), the income from the issue of the green bonds will be invested in the following areas, namely, renewable and sustainable energy, clean transportation, sustainable water management, climate change adaptation and mitigation, energy efficiency, sustainable waste management, sustainable land use, and biodiversity conservation (SEBI India, 2017). Just like any other issue in the debt capital market, the green bond market allows issuers in public or private sectors to raise capital for a definite period at a variable interest rate. The difference is that the green bond market finances only green projects or assets (Climate Bond Initiative, 2015; Hyun et al., 2020).

The green bond market was kicked off in 2007. Since then, various types of green bonds have been issued. Since this diversity of green bonds appeals to a diverse investor base, it is a major factor contributing to the green bond market's rapid expansion. This paper aims to fill the literature gap by exploring various factors that are influencing the Indian retail investors' investment decisions through various analyses. The results, it is hoped, will help the policymakers, industries, and financial institutions overcome the challenges in increasing the participation of retail investors in green bonds.

\section{LITERATURE REVIEW}

Government policies designed to achieve LCR economy and Nationally Determined Contribution (NDC) targets have triggered green bond issues worldwide. The previous study shows that green bond issues and allocations have been significantly affected by policies and NDC targets (Tolliver et al., 2020). It must be noted that, in the emerging markets, raising funds from institutional investors such as banks and NBFCs is increasingly constrained by Basel norms (Dutt et al., 2019). Therefore, to raise funds from the public, broadening the investor base becomes necessary. Since the 1970s, the continuous debt waves have led to three financial crises: the Latin American debt crisis, the Asian Financial crisis, and the Global Financial crisis during 1980, late 1990, and from 2007 to 2009, respectively. The fourth debt wave that started in 2010 has reached US\$ 55 trillion in 2018, which re- sulted in the failure to raise public finance (Kose et al., 2020), therefore, exploration of new sources of capital.

Large-scale private capital investment in green bonds is an attractive option if banks and other financial institutions cannot lend funds. The next best option for the borrowers is the bond market, as elucidated by Srinivasulu Yanamandra in one of the IFR seminars (IFRA, 2018). Including private finance can reduce the inefficiency of public finance. Inefficiency can be in terms of overallotment to increase or maintain the political strength and funding to limited projects at the expense of other projects, which can have potentially higher socioeconomic returns (Ball et al., 2007; Wang et al., 2018). On the other hand, private finance comes with its own inefficiencies, such as the inability to look at long-term profit, a diverse range of stakeholders, etc. (Corfee-morlot et al., 2012). This 
and the major hurdle that further restrains the investment are the prejudices of the private investors and cognitive biases of the individual investors.

The academic literature is in the nascent stage in the field of green bonds. The theories regarding investors' motivation to invest in green bonds are mainly related to social, financial, and institutional factors. For socially responsible investors, personal and social values take precedence over profit maximization (Derwall et al., 2011). However, the motivation of investing in green bonds is more related to financial and institutional factors. Globalization has raised multiple environmental and social challenges. Consequently, global investors have greater awareness to consider social and environmental aspects before investing (Jansson \& Biel, 2011). Large institutional investors also consider green investing to ensure long-term economic efficiency and sustainability by shifting towards viable and sustainable investments (Hawley \& Williams, 2002). The motivation to invest in green bonds is also related to institutional factors as institutions facing the same conditions tend to adopt similar actions because ideally, these institutions have to respond to related multiple stakeholders (Unerman \& Bennett, 2004; Deegan, 2009).

The green bond market in India is at the emerging stage. Therefore, it is essential to optimize the green bond market growth by attracting various investors to it to provide sustainable finance (Jha \& Bakhshi, 2019). Climate Bond Initiative (CBI) has kept a close eye on green bonds since 2009 . Types of green bonds identified by the Natural Resources Defense Council (NRDC) are as follows: high-yield green bond, corporate green bond, municipal green bond, and commercial bank green bond (Ghosh et al., 2016). High-yield green bond helps the issuers to give a more robust set of green investing tools to the investors and helps the issuers to tap into the various investor segments. NRG Yields, an American energy company, issued the first high-yield green bond for US\$ 500 million in August 2014. Corporate green bonds help corporates invest in reducing their environmental footprint and attract investors who value the natural environment (Flammer, 2018). Municipal green bonds are issued by local governments, cities, or other municipal bodies and their agencies. The first municipal green bond was issued in the US in 2014 to invest in a sustainable water project. Many such bodies followed this in other developed countries in Europe (GIZ India, 2017). Commercial banks issue green bonds usually to finance green projects, mostly renewable energy projects such as solar energy. Majorly green bonds are used to finance renewable energy projects; this and studies have proved that the energy and the environment values share a positive correlation with the greenness of the green bond (Kanamura, 2020; Agarwal \& Singh, 2018).

Over the last decade, green bonds have emerged as an innovative financial instrument that can bring private and public players together to build a sustainable world (Banga, 2019; Rose, 2019). Due to investors' broad base such as mainstream institutional investors, special Environmental, Social, and Governance (ESG) factors and responsible investors, corporate treasure, municipal government, retail investors, etc. (Climate Bond Initiative, 2020). Green bonds can tap into a large source of capital (De Mariz \& Deschryver, 2020). However, investment by retail investors in green bonds is very low in India. That is why this paper explores the reasons and the attributes of the retail investors that keep them away from the green bond market. This research aims to know the preference of the individual retail investors, a section that constitutes a large potential source of capital for financing the transition towards an LCR economy through the green bond market. The study further aims to investigate the effectiveness of the different factors on individual retail investors' decision to invest in green bonds and further analyze the importance of the financial and environmental factors, which influence the retail investors.

\section{HYPOTHESES DEVELOPMENT}

Several researchers have investigated the several factors that affect investment decisions. Nagy and Obenberger (1994) showed that factors such as earnings, diversification, firm's reputation, minimum risk, tax consequences, etc., are frequently considered by the investors. The study aims to identify the effectiveness of different factors in the investment decision; therefore, the hypotheses contain only some critical factors. The importance 
of these factors and the reasons for their inclusion are explained in the following paragraphs.

In India, the financial instruments popular among retail investors are bank deposits, mutual funds, provident funds, and insurance (World Bank, 2006). This suggests that retail investors are less exposed to the bond market, which reduces the investors' confidence. The results also suggest that in the emerging market where investors have little exposure to long-term investments, leveraging this capital is a challenge (International Finance Corporation \& Amundi Asset Management, 2018). This is where various tenure ranges come in handy by providing investors with options to choose the investment term. This also enhances the liquidity of the market. For example, IREDA had issued tax-free bonds in January 2016 of various tenures ranging from 10 to 20 years and bearing various coupon rates (Mudgill, 2016b). This issue was oversubscribed 1.84 times by the retail investors(according to the report, overall, it was oversubscribed by 5.09 times). This shows the extent of the interest of the investors in green bonds (Mudgill, 2016a). The issue successfully reached various types of investors, including individual retail investors and high net worth individuals. Note that this tax-free bond provides better interest rates than the banks. The interest paid by banks is subject to tax, which may have been a reason for the oversubscription of the issue. According to research, tax incentives can play a critical role in mobilizing retail savings for sustainable growth projects in India (Harikumar \& D, 2017). Tax-free bonds are also considered risk-free because government-backed entities issue them and, therefore, the bond market is led by the government securities (Hasnat \& Ashraf, 2018). Thus, the hypothesis proposed is as follows:

\section{H1: Individuals' decision to invest in green bonds is affected by the various tenure ranges and government push such as tax incentives.}

As for risk, according to Jha and Bakhshi (2019), multiple risks attach to green finance, such as currency risk, technology risk, environmental risk, etc. According to Diouf et al. (2016), there is a direct relationship between the ESG issues and responsible investment. More awareness of these issues makes individuals more inclined to invest responsibly. Also, the awareness of climate change and environmental factors is rising among individuals. This is a prevalent reason for behavioral changes among individuals (R. \& H., 2010). This growing awareness makes both investors and issuers look into these factors. Verma and Agarwal (2020) showed that awareness of green bonds is a critical factor to be considered while talking about the growth of the green bond market. Diouf et al. (2016) suggested that the ESG issue is an important factor in influencing an individual's investment decision. The study also found that many investors believe that, for them, financial return is essential. However, that does not exclude the influence of ESG factors on their investment decision. Nanayakkara's work also suggests that the "greenness" of the bond makes investors willing to pay a positive premium (Nanayakkara \& Colombage, 2019). It has been found that the prices of the stocks of the companies that issue the green bond and practice ESG activities in their processes rise in the stock market (Tang \& Zhang, 2020), which, in turn, attracts more investors to invest in these companies. However, the challenge in augmenting the green bond market is in the lack of awareness of the merits of green bonds among the investors and, in some cases, of green bonds (Harikumar \& D, 2017). This was further supported by Jha and Bakhshi (2019) who stated that lack of awareness about the different types of innovative financial instruments is one of the critical hurdles in green finance.

The information helps in making viable investment decisions. Investment decisions can have financial and emotional consequences in the long run (Kahneman \& Riepe, 1998). Green bond reporting and assurance of the third-party help the issuers reveal more information on how the income would be used, leading to greater transparency (ICMA, 2015). An empirical study was done in China (Wang et al., 2019). It showed that the third-party assurance and the risk premium of the green bond share a negative relationship. This means third-party assurance helps to reduce the risk. A study also suggests that minimizing the risk is an essential factor that individual investors consider while making the investment decision (Nagy \& Obenberger, 1994). Wang et al. (2019) also suggested that the third-party certificate helps reduce the risk and make green bonds more credible. However, 
recent research on green bonds in Sweden suggested that this added cost of increasing the transparency and obtaining the certificate creates a negative impact on the issuer's cost of capital (Maltais \& Nykvist, 2020). Rating agencies consider different types of risks, such as default risk, sovereign risk, etc., while deciding the issuers' credit ratings or the bond ratings. This also helps the investors make investment decisions and encourages the bond market's growth (Verma \& Agarwal, 2020). Thus, the following hypotheses are proposed:

H2: Expected financial benefits affect individuals' decisions to invest in green bonds.

H3: Individuals' decision to invest in green bonds is affected by the environmental benefits expected from transparent utilization of the proceeds and reporting obligation (ESG ratings) and the creditworthiness of the issuer.

H4: Individuals' decisions for investing in green bonds are affected by the individuals' exposure to green bonds (awareness).

Zerbib (2019) found that the investors were willing to give up on $1.5 \%$ of the average yield while investing in the green bond. However, according to the past studies, there is no research on the part-worth utility of environmental benefits by the Indian retail investors who invest in the green bond. Therefore the hypothesis proposed is:

H5: Investors are placing greater importance on environmental benefits than on financial benefits.

\section{METHODOLOGY}

This paper uses a research design that includes two methods, qualitative method and quantitative method, and it has been divided into three parts. To place the empirical study framework in the foremost phase, we developed an understanding of the main issue, identified the problems related to green bonds, and examined the investors' behavior through documented analysis and literature review. In this analysis, the behavioral finance literature has received special attention to validate the variables (Monasterolo \& Raberto, 2017).
Investors with diverse profiles participated in this study and provided their insights through their responses to the questionnaire. The survey was conducted in July 2020. To substantiate the measurement scale and rectify the survey instrument, a pre-test with a limited number of respondents was performed before floating the survey. The survey was floated on various digital platforms so that it reached the right set of respondents. At the beginning of the survey, the respondents were informed about green bonds, and the respondents' consent for participating in the survey was obtained. The respondents were assured that the information collected was for academic purposes only, and the respondents' identities would remain confidential.

Responses to the questionnaire were received from 206 respondents. However, responses from 81 respondents were incomplete or unreliable and, hence, were discarded. As a result, 125 responses were retained for the analysis. The survey testing helped eliminate unnecessary questions and reduced error by enhancing clarity by reformulating the unclear questions.

In the second part of the study, the Indian individual investors were asked, through different channels, to participate in a pre-tested web-based survey questionnaire. In the third part, of the collected data was subjected to multivariate regression analysis, multinomial logistic regression analysis, and conjoint analysis. To understand the trade-off, researchers are very inclined to use conjoint analysis. The purpose of the questionnaire was to collect the data and develop a valid measurement of individual preference expressed on a Likert scale so that the derived conclusion might help build the base for further research and the green bond market growth. This paper is the earliest attempt to understand and know the individual investors' preference for green bonds in India (although similar research was done in Sweden by Kivikoski and Sandberg in 2019).

The questionnaire was divided into three sections and includes more than 20 questions. The first section asked for the respondents' background information and was used to verify their eligibility as respondents concerning the research area. This section enquired the respondents' location, age, and gender. The second section sought 
to know the level of respondents' awareness about green bonds, their preferences for channels of investment, and their attitude while investing. This section was dedicated to finding the effectiveness of factors that influence the investment decision. The questions in these sections were designed for the regression analysis. In the questionnaire, the greenness of the bond was specially defined to avoid any misunderstanding and error in the measurement. The third section was dedicated to finding the trade-off and the importance of the factors and was formulated to meet conjoint analysis requirements.

To achieve the results, a linear regression model was developed, which is as follows:

$$
\begin{aligned}
& y=\beta_{\text {const. }}+\left(\beta_{1} \cdot v_{1}\right)+\left(\beta_{2} \cdot v_{2}\right)+ \\
& +\left(\beta_{3} \cdot v_{3}\right)+\left(\beta_{4} \cdot v_{4}\right)+\left(\beta_{5} \cdot v_{5}\right)+ \\
& +\left(\beta_{6} \cdot v_{6}\right)+\left(\beta_{7} \cdot v_{7}\right),
\end{aligned}
$$

where $y$ is the dependent variable, i.e., investment decision in the green bond, $v_{1}$ is the ESG rating of the issuer, $v_{2}$ is the tax incentives, $v_{3}$ is awareness of the green bond, $v_{4}$ is the credit rating of the issuer, $v_{5}$ is the maturity period, $v_{6}$ is the benefits to the environment, and $v_{7}$ is interest rate. The $\beta$ values are the values that show the impact that the variable has on the dependent variable, i.e., investment decision in green bond, while all other variables are constant. It is also known as the partial regression coefficient.

The variables in the linear regression model were operationalized using the quantitative indicators and psychological scale. As mentioned earlier, section two was formulated to be suitable for regression analysis. Therefore, most questions in this section were designed as direct questions to eliminate researcher bias. Respondents were first asked to indicate their extent of agreement towards three statements about the awareness of green bonds and the individual's investment behavior in green bonds. Furthermore, respondents were asked to show the extent of their agreement, on a 5-point Likert scale, regarding the factors, which might influence their investment decision. These questions were designed using the cognitive psychology approach for assessment and influence of the factors (Wagner, 1997). These six variables were then subjected to forward regression analysis, which resulted in eliminating one of the variables due to high error.

Preference of the individual retail investors was assessed employing the importance they placed on the following variables while making an investment decision, (a) credit rating of the issuer, (b) ESG ratings of issuer, (c) interest rate, (d) environmental benefits from the project, (e) maturity period, (d) tax incentives or exemptions. A detailed analysis of the preference was conducted using conjoint analysis.

Table 1. Attributes and attributes level

\begin{tabular}{c|c}
\hline \multicolumn{1}{c}{ Attributes } & Levels \\
\hline Greenness of bond & L1: High \\
& L2: Medium \\
& L3: Low \\
Interest rate & L1: at $7.5 \%$ \\
& L2: at $8.00 \%$ \\
\hline & L3: at $8.5 \%$ \\
\hline & L1: 10 years \\
\hline & L2: 15 years \\
\hline
\end{tabular}

In the third section of the questionnaire, respondents were asked to rank the green bonds. Each green bond represented the combination of three attributes as follows: (a) greenness of bond, (b) interest rate, and (c) maturity period. These three attributes also assigned three levels, which resulted in 27 combinations. To reduce the respondents' unwillingness to ranking these green bonds that had various combinations of attributes, a final combination of up to nine possible best attributes from among the attributes was chosen as presented in Table 1. These choices were developed using orthogonal design, employing a small but representative set of combinations for research (Fang \& Lin, 2003; Gong et al., 2008).

One way to explain the data produced through this questionnaire is that each column will show the ratings of a unique combination of three attributes. However, the data required for the conjoint analysis could be derived by two different techniques, namely, effect coding and dummy coding (Bech \& Gyrd-Hansen, 2005; Hauber et al., 2016). In both of these techniques, value 1 is assigned when the attribute level exists in the profile, value 0 is assigned if the non-excluded level exists 
in the profile. The difference between the dummy coding and effect coding lies in assigning the value to the attribute's excluded level. In dummy coding, the value 0 is assigned when the excluded level of an attribute is present. Simultaneously, in effect coding, the value of -1 is assigned when the omitted level of an attribute is present. In this study, the dummy variables have been developed using the effect coding approach to arrive at a statistically better interpretation of the constants (Bech \& Gyrd-Hansen, 2005).

\section{RESULTS}

A total of 125 valid responses were collected and analyzed in line with the objectives of the study. Table 1 exhibits the respondents' descriptive statistics, which evidence that the sample was diverse in terms of demographics of the investors, level of experience in the bond market, and the age group. These results suggested that the responses were quite suitable for performing regression analysis. The data in Table 2 indicate that approximately $25.60 \%$ of the respondents invested in the bond market. Also, $35.20 \%$ of the respondents belonged to the age group of 27 to 39 years, and $17.60 \%$ were older than 40 years. It showed that the investors had quite enough pertinent experience in the bond market. Regarding the preference for investment, the sample was very much varied. Although around $81 \%$ of the investors preferred to invest in green bonds for the financial benefit, and $40 \%$ of the investors preferred to invest in the green bond market for the environmental benefit. The responses were collected from 18 different states of India, though most respondents lived in the Indian states of Gujarat and Maharashtra. Since the responses were collected using the snowball technique, $52.80 \%$ of the responses were collected from the above two states.

Table 2. Descriptive statistics of the research sample

\begin{tabular}{l|c|c}
\hline \multirow{2}{*}{ Variables } & \multicolumn{2}{c}{ Research sample } \\
\cline { 2 - 3 } & Age group of investors \\
\hline Bellow 18 & 0 & $\%$ \\
\hline 19 to 27 & 59 & 0.00 \\
\hline 27 to 39 & 44 & 47.20 \\
\hline 40 to 50 & 8 & 35.20 \\
\hline Above 51 & 14 & 6.40 \\
\hline
\end{tabular}

\begin{tabular}{|c|c|c|}
\hline \multirow{2}{*}{ Variables } & \multicolumn{2}{|c|}{ Research sample } \\
\hline & $\mathbf{N}$ & $\%$ \\
\hline \multicolumn{3}{|c|}{ Investment in bond } \\
\hline Yes & 32 & 25.60 \\
\hline No & 75 & 60.00 \\
\hline Maybe & 16 & 12.80 \\
\hline Prefer not to say & 2 & 1.60 \\
\hline \multicolumn{3}{|c|}{ Country } \\
\hline India & 125 & 100.00 \\
\hline Other & 0 & 0.00 \\
\hline \multicolumn{3}{|c|}{ Current state of residence } \\
\hline Gujarat & 46 & 36.80 \\
\hline Maharashtra & 20 & 16.00 \\
\hline Rajasthan & 11 & 8.80 \\
\hline Delhi & 9 & 7.20 \\
\hline Uttar Pradesh & 7 & 5.60 \\
\hline Others & 32 & 25.60 \\
\hline \multicolumn{3}{|c|}{ Invest in the improvement of the environment } \\
\hline Strongly disagree & 4 & 3.20 \\
\hline Disagree & 19 & 15.20 \\
\hline Neutral & 50 & 40.00 \\
\hline Agree & 37 & 29.60 \\
\hline Strongly agree & 15 & 12.00 \\
\hline \multicolumn{3}{|c|}{ Invest for financial benefits } \\
\hline Strongly disagree & 4 & 3.20 \\
\hline Disagree & 3 & 2.40 \\
\hline Neutral & 16 & 12.80 \\
\hline Agree & 51 & 40.80 \\
\hline Strongly agree & 51 & 40.80 \\
\hline \multicolumn{3}{|c|}{ Willingness to invest in green bond } \\
\hline Very unlikely & 1 & 1 \\
\hline Unlikely & 11 & 9 \\
\hline Neutral & 24 & 19 \\
\hline Likely & 64 & 51 \\
\hline Very likely & 25 & 20 \\
\hline
\end{tabular}

In support of the background study on green bonds, the paper also arrived at several fascinating findings. The study points out that $52 \%$ of the respondents who were very likely to invest in green bonds agreed strongly with the statement that they would invest their funds for their financial benefits. This analysis suggests that $40.45 \%$ of the respondents who were likely or very likely to invest in green bonds agreed or strongly agreed with the statement that they would invest their funds to improve the environment. This result shows that both types of retail investors look at green bonds as an innovative financial tool and are ready to invest their funds in the green bond market.

Using SPSS analytical software, this model was developed such that the correlation of the factor which enters into the model would be within the 
confidence interval of $95 \%$ so that the reliability of the results could be better. This means it was accepted that the correlation coefficient was significant only when it was less than $5 \%$. Table 3 shows the $R$-squared value, which indicates the "goodness of fit", that is, how good the data are for developing this model. In this case, the analysis showed that the software continued to develop the model until it achieved the maximum $R$-squared value so that maximum data could be used to extract the results. In Table 3, model 6 is seen to have the maximum $R$-squared value of $68.7 \%$. It indicated that model 6 could achieve the optimal results from the data. Therefore, model 6 was used as the regression model.

Table 3. Regression model summary

\begin{tabular}{c|c|c|c|c}
\hline Model & $\boldsymbol{R}$ & $\boldsymbol{R}$-squared & $\begin{array}{c}\text { Adjusted } \\
\boldsymbol{R} \text {-squared }\end{array}$ & $\begin{array}{c}\text { Std. error of } \\
\text { the estimate }\end{array}$ \\
\hline 1 & .675 & .456 & .451 & .656 \\
\hline 2 & .738 & .545 & .537 & .603 \\
\hline 3 & .776 & .603 & .593 & .566 \\
\hline 4 & .809 & .654 & .643 & .530 \\
\hline 5 & .821 & .675 & .661 & .516 \\
\hline 6 & .829 & .687 & .671 & .508 \\
\hline
\end{tabular}

Table 4. Output of regression analysis

\begin{tabular}{|c|c|c|c|c|c|}
\hline & \multirow{2}{*}{ Model } & \multicolumn{2}{|c|}{$\begin{array}{c}\text { Unstandardized } \\
\text { coefficients }\end{array}$} & \multirow{2}{*}{$\mathbf{t}$} & \multirow{2}{*}{ Sig. } \\
\hline & & $\beta$ & $\begin{array}{l}\text { Std. } \\
\text { error }\end{array}$ & & \\
\hline \multirow{7}{*}{6} & (Constant) & .110 & .263 & .420 & .675 \\
\hline & $\begin{array}{l}\text { ESG ratings of the } \\
\text { issuer }\end{array}$ & .228 & .050 & 4.596 & .000 \\
\hline & Tax incentive & .183 & .061 & 2.972 & .004 \\
\hline & $\begin{array}{l}\text { Awareness of green } \\
\text { bonds }\end{array}$ & .209 & .045 & 4.590 & .000 \\
\hline & Credit rating of issuer & .219 & .071 & 3.075 & .003 \\
\hline & $\begin{array}{l}\text { Maturity period of a } \\
\text { green bond }\end{array}$ & .144 & .059 & 2.427 & .017 \\
\hline & $\begin{array}{l}\text { Benefits to } \\
\text { environment }\end{array}$ & .081 & .038 & 2.150 & .034 \\
\hline
\end{tabular}

The above contradicts the findings of a previous study by Hasnat and Ashraf (2018), which showed that the bond market is very sensitive to the interest rate. The above results suggest that the interest rate is not an important factor for the retail investor.

Except for hypothesis $H 2$, all other hypotheses, $H 1, H 3, H 4$, and $H 5$, have been accepted, and the results suggest that the benefits for the environ- ment have a very low influence on the decision to invest in green bonds. Interestingly, the analysis shows that the tax incentives have a comparatively greater influence on individuals' investment decision. It suggests that incentivizing the green bond issues helps in attracting more investors to the green bonds market. The analysis also reveals that factors such as ESG ratings and credit ratings have the greatest influence on investment decisions. This supports the previous study by Li et al. (2019). Interestingly, awareness of the green bond also has a greater influence on the investment decision than expected. Table 4 shows that the highest error that this model accepted was 3.4\%, which is within the confidence interval. The regression model now can be developed through this table, using the unstandardized coefficient $\beta$ as follows:

$$
\begin{aligned}
& y=0.110+0.228 \cdot v_{1}+0.183 \cdot v_{2}+ \\
& +0.209 \cdot v_{3}+0.219 \cdot v_{4}+ \\
& +0.114 \cdot v_{5}+0.081 \cdot v_{6} .
\end{aligned}
$$

In this analysis, variables $1,2,3,4,5$, and 6 represent awareness of green bonds, the credit rating of the issuer, ESG ratings of the issuer, benefits to the environment by the project, the maturity period of the green bond and tax incentive/tax exemption, respectively. These variables are tested on the dependent variable of likeliness to invest in green bonds. Multinomial logistic regression analysis was used as the dependent variable that involved more than two categories. The dependent variable had five possible responses ranging from the least likelihood of investing to the greatest likelihood of investing (expressed on the scale from 1 to 5) and 5 being the reference category. The overall model was found to be significant $(p=0.001)$. The first set of coefficients represented the comparison between investors who were most and least likely to invest. Here, variable 5 was significant $(\beta=-1.224$, s.e. $=0.732, p=.094)$. The investor placing greater importance on the ESG rating of the bond issuer was less likely to be the least willing investor for green bonds. Similarly, in category 2, variable 4 and 6 were significant $(\beta=-1.075$, s. e. $=0.529$, $p=.042 ; \beta=-1.537$, s. e. $=0.734, p=.036)$. In category 3 , variables 2,3 , and 5 were significant $(\beta=-0.790$, s. e. $=0.464, p=.089 ; \beta=-1.028$, s. e. $=0.525, p=.050 ; \beta=-1.085$, s. e. $=0.534$, $p=.042$ ). In category 4 , variable 5 was significant $(\beta=-0.747$, s. e. $=0.444, p=.092)$. 
Table 5. Multinomial logistic regression output

\begin{tabular}{|c|c|c|c|c|c|c|c|c|c|}
\hline \multicolumn{2}{|c|}{$\begin{array}{l}\text { How willing are you to } \\
\text { invest in green bond?a }\end{array}$} & \multirow{2}{*}{$\begin{array}{c}\text { B } \\
11.645\end{array}$} & \multirow{2}{*}{$\begin{array}{c}\text { Std. error } \\
5.016\end{array}$} & \multirow{2}{*}{$\begin{array}{c}\text { Wald } \\
5.390 \\
\end{array}$} & \multirow{2}{*}{$\frac{\mathbf{d f}}{1}$} & \multirow{2}{*}{$\begin{array}{l}\text { Sig. } \\
.020\end{array}$} & \multirow{2}{*}{$\operatorname{Exp}(B)$} & \multicolumn{2}{|c|}{$\begin{array}{c}\text { 95\% confidence interval for } \\
\operatorname{Exp}(B)\end{array}$} \\
\hline \multirow{7}{*}{1.0} & Intercept & & & & & & & Lower bound & Upper bound \\
\hline & VAR1 & -.239 & .721 & .110 & 1 & .741 & .788 & .192 & 3.237 \\
\hline & VAR2 & -.570 & .673 & .716 & 1 & .397 & .566 & .151 & 2.117 \\
\hline & VAR3 & -1.286 & .846 & 2.311 & 1 & .128 & .276 & .053 & 1.451 \\
\hline & VAR4 & -.926 & .908 & 1.039 & 1 & .308 & .396 & .067 & 2.349 \\
\hline & VAR5 & -1.224 & .732 & 2.797 & 1 & .094 & .294 & .070 & 1.234 \\
\hline & VAR6 & .541 & .952 & .323 & 1 & .570 & 1.718 & .266 & 11.096 \\
\hline \multirow{7}{*}{2.0} & Intercept & 10.711 & 3.634 & 8.688 & 1 & .003 & & & \\
\hline & VAR1 & -.169 & .404 & .176 & 1 & .675 & .844 & .382 & 1.864 \\
\hline & VAR2 & -.140 & .564 & .062 & 1 & .804 & .869 & .288 & 2.624 \\
\hline & VAR3 & .965 & .628 & 2.365 & 1 & .124 & 2.626 & .767 & 8.987 \\
\hline & VAR4 & -1.075 & .529 & 4.131 & 1 & .042 & .341 & .121 & .962 \\
\hline & VAR5 & -.946 & .608 & 2.418 & 1 & .120 & .388 & .118 & 1.279 \\
\hline & VAR6 & -1.537 & .734 & 4.384 & 1 & .036 & .215 & .051 & .906 \\
\hline \multirow{7}{*}{3.0} & Intercept & 10.430 & 3.377 & 9.541 & 1 & .002 & & & \\
\hline & VAR1 & -.563 & .359 & 2.461 & 1 & .117 & .570 & .282 & 1.151 \\
\hline & VAR2 & -.790 & .464 & 2.896 & 1 & .089 & .454 & .183 & 1.127 \\
\hline & VAR3 & -1.028 & .525 & 3.831 & 1 & .050 & .358 & .128 & 1.001 \\
\hline & VAR4 & .070 & .492 & .020 & 1 & .886 & 1.073 & .409 & 2.814 \\
\hline & VAR5 & -1.085 & .534 & 4.121 & 1 & .042 & .338 & .119 & .963 \\
\hline & VAR6 & .488 & .662 & .545 & 1 & .460 & 1.629 & .446 & 5.959 \\
\hline \multirow{7}{*}{4.0} & Intercept & 8.537 & 2.841 & 9.032 & 1 & .003 & & & \\
\hline & VAR1 & -.203 & .234 & .751 & 1 & .386 & .816 & .515 & 1.292 \\
\hline & VAR2 & -.073 & .381 & .037 & 1 & .848 & .929 & .440 & 1.961 \\
\hline & VAR3 & .285 & .412 & .478 & 1 & .489 & 1.329 & .593 & 2.978 \\
\hline & VAR4 & -.419 & .367 & 1.303 & 1 & .254 & .658 & .320 & 1.351 \\
\hline & VAR5 & -.747 & .444 & 2.833 & 1 & .092 & .474 & .199 & 1.131 \\
\hline & VAR6 & -.694 & .525 & 1.748 & 1 & .186 & .499 & .178 & 1.398 \\
\hline
\end{tabular}

Note: a. The reference category is 5.0 .

Through conjoint analysis on the prepared dummy variables, the part-worth utility of financial benefits and the greenness of bond were checked, the result accepted the hypothesis $H 5$, which is shown in Table 7. Here the unstandardized coefficient $\beta$ suggests the part-worth utility of the dummy variables created and shown in Table 6. As discussed earlier in the paper, while preparing the data through effect coding, one level of each at- tribute was omitted, the result of conjoint analysis in Table 7 looks into those effect codes only.

It is necessary to solve the part-worth utility of the omitted variable. The part-worth utility is estimated on an interval scale so that the origin is arbitrary (Malhotra, 2019). So, the additional constrain that is imposed is in the following form:

Table 6. Dummy variables

\begin{tabular}{|c|c|}
\hline Dummy variable & Name of the dummy \\
\hline Dummy1 & High greenness \\
\hline Dummy2 & Medium greenness \\
\hline Dummy3 & Low greenness \\
\hline Dummy4 & Interest rate of $7.5 \%$ \\
\hline Dummy 5 & Interest rate of $8.0 \%$ \\
\hline Dummy6 & Interest rate of $8.5 \%$ \\
\hline Dummy7 & Maturity time 10 years \\
\hline Dummy8 & Maturity time 15 years \\
\hline Dummy 9 & Maturity time 20 years \\
\hline
\end{tabular}


Table 7. Output of the conjoint analysis

\begin{tabular}{|c|c|c|c|c|}
\hline \multirow{2}{*}{ Attribute } & \multicolumn{2}{|c|}{ Level } & \multirow{2}{*}{ Utility } & \multirow{2}{*}{ Importance } \\
\hline & No & Description & & \\
\hline \multirow{3}{*}{ Greenness of bond } & 1 & High & -0.941 & \multirow{3}{*}{1.941} \\
\hline & 2 & Medium & -0.059 & \\
\hline & 3 & Low & 1.000 & \\
\hline \multirow{3}{*}{ Interest rate of bond } & 1 & $7.50 \%$ & 0.272 & \multirow{3}{*}{0.643} \\
\hline & 2 & $8.00 \%$ & 0.099 & \\
\hline & 3 & $8.50 \%$ & -0.371 & \\
\hline \multirow{3}{*}{ Maturity period } & 1 & 10 years & -0.653 & \multirow{3}{*}{1.304} \\
\hline & 2 & 15 years & 0.003 & \\
\hline & 3 & 20 years & 0.651 & \\
\hline
\end{tabular}

Dummy1 + Dummy2 + Dummy3 $=0$

Dummy3 $=0-$ Dummy1 - Dummy2 $=1.000$

Dummy6 $=0-$ Dummy4 - Dummy5 $=-0.371$

Dummy9 $=0$ - Dummy7 - Dummy8 $=0.651$

The conjoint analysis result suggests that the highest utility and the greatest importance are assigned to the "greenness of bond" attribute, which also supports the result of the regression model. The conjoint analysis result contradicts the previous study that the investors are willing to invest their funds for a more extended period. The importance assigned to the maturity period is 1.304 . The importance of the attribute is calculated as the difference between the maximum utility assigned to the attribute and the minimum utility assigned to the attribute, which is as follows,

Importance of the greenness of bond:

$$
1.000-(-0.941)=1.941
$$

Importance of interest rate of bond:

$$
0.272-(-0.371)=0.643
$$

Importance of the maturity period:

$$
0.651-(-0.653)=1.304
$$

\section{DISCUSSION}

The transition towards an LCR economy demands immense funds. To overcome this financial bar- rier, there are several innovative green financial tools available (Soundarrajan \& Vivek, 2016). One of these tools is the green bond. Green bond has the power to emerge as a cheaper source of finance. However, the green bond market is still at a nascent stage. Although investors can play a critical role in the growth of this green bond market (Murphy, 2012), evidence suggests that the diversity in the investor base is significantly less. Therefore, many policies have been implemented, and many incentives have been given to stimulate this market. However, many of these efforts have been only moderately effective for the growth of this market because of failure to understand the factors which investors consider while making investment decisions.

In the market, the green bond issue's success relies heavily on the attractiveness of the bond, which, in turn, depends on individual behavior. To make the issue of green bonds successful in the future, understanding the psychological factors and how they influence the retail investors' investment decision is essential. Future studies can also investigate the investment decisions in the context of investor risk profiles. Surprisingly, among green bond literature, there is an absence of applied study that scrutinized these aspects of individuals' investment decision-making. Due to this, some of the key drivers of the investment decision process remain undiscovered.

\section{CONCLUSION}

The paper contributes to behavioral finance, bond market policy, and green finance literature and draws several crucial inferences. The analysis shows that the issuers' ratings and the creditworthiness of the issuers are the most critical factors that influence investors' investment decisions. These ratings can increase the efficiency and transparency of the market, which would ultimately help the issuer attract more investment by building investors' confidence in investment. This study also brings some interesting insights, particularly into the 
awareness of the green bond among Indian retail investors, which is also an important factor. An increase in awareness about green bonds will greatly affect the investment decisions of individuals. By increasing awareness, one can significantly influence market growth by influencing the investors. Policymakers can be the key influencers for the growth of this market by incentivizing green bond issuance. This study shows that extra incentives such as tax exemptions also greatly influence individuals' investment decisions.

Like any other research work, this paper also has a few limitations, such as generalizing the study might be difficult. It is focused on the retail investors only, the respondents were not equally distributed from all over the country, and most respondents were from two states of India. The study has found that a trade-off is available between the environmental benefit and financial benefits but has failed in quantifying the tradeoff. Many respondents intend to but have not yet invested in the bond market, which shows that the sample lacks experience of the Indian bond market. It is expected that these challenges and the limitations will be addressed in future research.

\section{AUTHOR CONTRIBUTIONS}

Conceptualization: Dhaval Prajapati, Dipen Paul, Sushant Malik, Dharmesh K. Mishra.

Data curation: Dhaval Prajapati, Dipen Paul, Sushant Malik, Dharmesh K. Mishra.

Formal analysis: Sushant Malik, Dipen Paul, Dhaval Prajapati.

Investigation: Dhaval Prajapati, Sushant Malik, Dharmesh K. Mishra.

Methodology: Dhaval Prajapati, Dipen Paul, Sushant Malik, Dharmesh K. Mishra.

Project administration: Dipen Paul.

Supervision: Dipen Paul.

Validation: Dipen Paul, Dharmesh K. Mishra, Sushant Malik.

Writing - original draft: Dhaval Prajapati, Dipen Paul, Sushant Malik, Dharmesh K. Mishra.

Writing - review \& editing: Dharmesh K. Mishra.

\section{REFERENCES}

1. Agarwal, S., \& Singh, T. (2018). Unlocking the green bond potential in India. Retrieved from http://archive.nyu.edu/handle/2451/42243

2. Ball, R., Heafey, M., \& King, D. (2007). The private finance initiative in the UK. Public Management Review, 9(2), 289-310. https://doi. org/10.1080/14719030701340507

3. Bech, M., \& Gyrd-Hansen, D. (2005). Effects coding in discrete choice experiments. Health Economics, 14(10), 1079-1083. https://doi.org/10.1002/hec.984

4. Climate Bond Initiative. (2015). Bond and climate change: The state of market in 2015.

5. Climate Bond Initiative. (2020). Investor appetite. Retrieved from https://www.climatebonds.net/ market/investor-appetite

6. Corfee-morlot, J., Marchal, V., \& Dahou, K. (2012). Towards a green investment policy framework: The case of low-carbon, climateresilient infrastructure. OECD Staff Consultation Draft, 18 June 2012, 02(September). Retrieved from http://www.oecd.org/ environment/cc/Towards $\% 20$ a\%20Green\%20Investment $\% 20$ Policy\%20Framework_consultation\%20draft\%2018-06-2012.pdf

7. De Mariz, F., \& Deschryver, P. (2020). What future for the green bond market? How can policymakers, companies, and investors unlock the potential of the green bond market? Journal of Risk and Financial Management, 13(3), 61. https://doi.org/10.3390/ jrfm13030061

8. Deegan, C. (2009). Financial accounting theory. McGraw Hill.

9. Derwall, J., Koedijk, K., \& Ter Horst, J. (2011). A tale of valuesdriven and profitseeking social investors. Journal of Banking and Finance, 35(8), 2137-2147. https://doi.org/10.1016/j.jbankfin.2011.01.009

10. Diouf, D., Hebb, T., \& Touré, E. H. (2016). Exploring factors that influence social retail investors' decisions: Evidence from Desjardins Fund. Journal of Business Ethics, 134(1), 45-67. https://doi.org/10.1007/s10551014-2307-4

11. Dutt, A., Soman, A., \& Chawla, K. (2019). Financing India's energy transition a guide on green bonds (Issue June).

12. Fang, K. T., \& Lin, D. K. (2003). Ch. 4. Uniform experimental designs and their applications in industry. Handbook of statistics, 22, 131-170. https://doi.org/10.1016/ S0169-7161(03)22006-X

13. Flammer, C. (2018). Corporate green bonds (Working Paper). Boston University. 
14. Ghosh, A. et al. (2016). Greening India's financial market: How green bonds can drive clean energy deployment. National Research Defence Council.

15. GIZ India. (2017). Green Municipal Bonds in India: Potential, Barriers and Advantages. Deutsche Gesellschaft für Internationale Zusammenarbeit (GIZ) GmbH.

16. Gong, W., Cai, Z., \& Jiang, L. (2008). Enhancing the performance of differential evolution using orthogonal design method. Applied Mathematics and Computation, 206(1), 5669. https://doi.org/10.1016/j. amc.2008.08.053

17. Government of India. (2015). India's Intended Nationally Determined Contribution. Government of India Ministry of Environment, Forest and Climate Change.

18. Halady, I. R., \& Rao, P. H. (2010). Does awareness to climate change lead to behavioral change? International Journal of Climate Change Strategies and Management, 2(1), 6-22. https://doi. org/10.1108/17568691011020229

19. Harikumar, P. N., \& D, S. (2017). Green bonds : Sustainable investment opportunities. International Journal of Scientific Research, 6(12), 325-328. https:// doi.org/10.36106/ijsr

20. Hasnat, T., \& Ashraf, S. (2018). Is government borrowing crowding out long term debt resources: An empirical enquiry from India. International Journal of Emerging Markets, 13(6), 17191731. https://doi.org/10.1108/ IJoEM-05-2017-0171

21. Hauber, A. B., González, J. M., Groothuis-Oudshoorn, C. G. M., Prior, T., Marshall, D. A., Cunningham, C., IJzerman, M. J., \& Bridges, J. F. P. (2016). Statistical methods for the analysis of discrete choice experiments: A report of the ISPOR conjoint analysis Good Research Practices Task Force. Value in Health, 19(4), 300-315. https://doi.org/10.1016/j. jval.2016.04.004
22. Hawley, J. P., \& Williams, A. T. (2002). The universal owner's role in sustainable economic development. Corporate Environmental Strategy, 9(3), 284291.

23. Hyun, S., Park, D., \& Tian, S. (2020). The price of going green: the role of greenness in green bond markets. Accounting and Finance, 60(1), 73-95. https://doi. org/10.1111/acfi.12515

24. ICMA. (2015). Green bond principles, 2015: Voluntary process guidelines for issuing green bonds. International Capital Market Association.

25. IFRA. (2018). India debt capital markets roundtable. In International Financing Review Asia (pp. 1-20). Retrieved from https://www.ifre.com/ story/1512115/ifr-asia-indiadebt-capital-markets-roundtable2018-first-panel-outlook-forfixed-income-lzyjxptmxv

26. International Finance Corporation, \& Amundi Asset Management. (2018). Emerging market green bonds report 2018 .

27. Jansson, M., \& Biel, A. (2011). Motives to engage in sustainable investment: A comparison between institutional and private investors. Sustainable Development, 19(2), 135-142. https://doi. org/10.1002/sd.512

28. Jha, B., \& Bakhshi, P. (2019). Green finance: Fostering sustainable development in India. International Journal of Recent Technology and Engineering, 8(4), 3798-3801. https://doi. org/10.35940/ijrte.d8172.118419

29. Kahneman, D., \& Riepe, M. W. (1998). Aspects of investor psychology. The Journal of Portfolio Management, 24(4), 52-65. https://doi.org/10.3905/ jpm.1998.409643

30. Kanamura, T. (2020). Are green bonds environmentally friendly and good performing assets? Energy Economics, 88, 104767. https://doi.org/10.1016/j.eneco.2020.104767

31. Kivikoski, L., \& Sandberg, R. (2019). Individual Investors'
Preferences Regarding Green Bonds (Student Thesis, UMEA University). Retrieved from http://urn.kb.se/ resolve?urn=urn:nbn:se:umu:diva$165057 \% 0 \mathrm{~A}$

32. Kose, M. A., Nagle, P., Ohnsorge, F., \& Sugawara, N. (2020). Global waves of debt. Retrieved from https://www.worldbank.org/en/research/publication/waves-of-debt

33. Li, Z., Tang, Y., Wu, J., Zhang, J., \& Lv, Q. (2019). The interest costs of green bonds: Credit ratings, corporate social responsibility, and certification. Emerging Markets Finance and Trade, 0938. https://doi.org/10.1080/154049 6X.2018.1548350

34. Malhotra, N. K. (2019). Marketing research: An applied orientation (Pearson paperback, 7th ed.). Thomas Press India Ltd. Retrieved from https://www.pearson.com/ us/higher-education/program/ Malhotra-Marketing-ResearchAn-Applied-Orientation-7thEdition/PGM1747830.html

35. Maltais, A., \& Nykvist, B. (2020). Understanding the role of green bonds in advancing sustainability. Journal of Sustainable Finance and Investment, 1-20. https://doi.org/1 0.1080/20430795.2020.1724864

36. Monasterolo, I., \& Raberto, $\mathrm{M}$. (2017). The EIRIN flow-of-funds behavioural model of green fiscal policies and green sovereign bonds. Ecological Economics, 144(July 2017), 228-243. https:// doi.org/10.1016/j.ecolecon.2017.07.029

37. Mudgill, A. (2016a). IREDA bonds got subscribed 5 times: What's drawing investors. The Economic Times. Retrieved from https://economictimes. indiatimes.com/markets/bonds/ ireda-bonds-got-subscribed5-times-whats-drawing-investors/ articleshow/50509756.cms?utm source $=$ contentofinterest\&utm medium=text\&utm campaign $=$ cppst

38. Mudgill, A. (2016b). IREDA taxfree bonds offer up to $7.68 \%$, open tomorrow. The Economic Times. Retrieved from https://economictimes.indiatimes.com/markets/ 
bonds/ireda-tax-free-bondsoffer-up-to-7-68-open-tomorrow/ articleshow/50479756.cms?utm source $=$ contentofinterest\&utm medium=text\&utm campaign $=$ cppst

39. Murphy, A. (2012). Biologyinduced effects on investor psychology and behavior. International Review of Financial Analysis, 24, 20-25. https://doi. org/10.1016/j.irfa.2012.07.001

40. Nagy, R. A., \& Obenberger, R. W. (1994). Factors influencing individual investor behavior. Financial Analysts Journal, 50(4), 63-68. https://doi.org/10.2469/faj. v50.n4.63

41. Nanayakkara, M., \& Colombage, S. (2019). Do investors in green bond market pay a premium? Global evidence. Applied Economics, 51(40), 4425-4437. https://doi.org/ 10.1080/00036846.2019.1591611

42. Planning Commission Government of India. (2014). The final report of the expert group on low carbon strategies for inclusive growth.

43. Rose, P. (2019). Green marketmakers: Sovereigns as catalysts for sustainable development. SSRN Electronic Journal, 516. https://doi. org/10.2139/ssrn.3471516
44. SEBI India. (2017). Disclosure requirements for issuance and listing green bonds.

45. Soundarrajan, P., \& Vivek, N. (2016). Green finance for sustainable green economic growth in India. Agricultural Economics, 62(1), 35-44. https:// doi.org/10.17221/174/2014-AGRICECON

46. Tang, D. Y., \& Zhang, Y. (2020). Do shareholders benefit from green bonds? Journal of Corporate Finance, 61(March), 1-18. https://doi.org/10.1016/j.jcorpfin.2018.12.001

47. Tolliver, C., Keeley, A. R., \& Managi, S. (2020). Policy targets behind green bonds for renewable energy: Do climate commitments matter? Technological Forecasting and Social Change, 157(March), 1-11. https://doi.org/10.1016/j. techfore.2020.120051

48. Unerman, J., \& Bennett, M. (2004). Increased stakeholder dialogue and the internet: Towards greater corporate accountability or reinforcing capitalist hegemony? Accounting, Organizations and Society, 29(7), 685-707. https://doi. org/10.1016/j.aos.2003.10.009

49. Verma, A., \& Agarwal, R. (2020). A study of green bond market in India: A critical review. IOP
Conference Series: Materials Science and Engineering, 804(1). https://doi.org/10.1088/1757899X/804/1/012052

50. Wagner, S. (1997). Understanding Green Consumer Behaviour: A Qualitative Cognitive Approach. https://doi. org/10.4324/9780203444030

51. Wang, H., Xiong, W., Wu, G., \& Zhu, D. (2018). Publicprivate partnership in public administration discipline: A literature review. Public Management Review, 20(2), 293316. https://doi.org/10.1080/14719 037.2017.1313445

52. Wang, Q., Zhou, Y., Luo, L., \& Ji, J. (2019). Research on the factors affecting the risk premium of China's green bond issuance. Sustainability, 11(22), 1-14. https:// doi.org/10.3390/su11226394

53. World Bank. (2006). Developing India's corporate bond market. Washington, DC. Retrieved from https://openknowledge.worldbank. org/handle/10986/19625

54. Zerbib, O. D. (2019). The effect of pro-environmental preferences on bond prices: Evidence from green bonds. Journal of Banking and Finance, 98, 39-60. https:// doi.org/10.1016/j.jbankfin.2018.10.012 